\title{
The Relationship Between Stakeholders and Corporate Reputation in the Education Industry
}

\author{
Russel Wei Wern \\ Faculty of Business, Curtin University Malaysia, CDT 250, Miri 98009, Malaysia \\ *Correspondence: 700034579@student.curtin.edu.my
}

SUBMITTED: 15 November 2021; REVISED: 23 November 2021; ACCEPTED: 23 November 2021

\begin{abstract}
This paper analyses the relationship between Stakeholders and Corporate Reputation in the Education Industry. Through the qualitative research methodology of surveys, responses from stakeholders of different levels in the education industry has been analysed. More specifically, the areas of corporate reputation analysed were stakeholders' management, stakeholder communication, Integrating Stakeholder Management and Communication to become Stakeholder Engagement, corporate reputation, image and identity and reputation and trust. From the analysed survey, it was found that engagement through actions of the organisations towards its stakeholders creates value and trust as two-way symmetrical communication for greater decision making.
\end{abstract}

KEYWORDS: Education industry; stakeholder communication; corporate reputation; decision making

\section{Introduction}

What was your initial impression of the university? And how has this affected your current status as a student or employee at a higher education institution?" I'd like to attract attention to the keyword "First Impression" that I included in this inquiry. Why? Because the "first impression" we had when we first heard about Higher institution is Higher institution's Corporate Reputation, and it's something about which we, as stakeholders, may have differing viewpoints and perspectives. For example, a student on scholarship may have a positive perception of a higher education institution's corporate reputation, but a student on the verge of failing may have a negative perception.

Through a series of interviews with experts in the education industry, the direct relationship between stakeholders and company reputation was discussed. As we readers are stakeholders in the higher education market, this method portrays not just a holistic but accessible study of how stakeholders determine company reputation in a public relations setting. I've sent out a series of anonymous interview requests to students, parents, lecturers, high-school teachers, colleagues in higher education, and ex-colleagues from a kindergarten where I used to work part-time for this research, and I'll relay their recorded thoughts and opinions on how this "first impression" of stakeholders truly determines corporate reputation. 


\section{Stakeholder Management}

"What is the point of understanding stakeholders if we do not organise them? For example, firstborn parents and second child parents are totally different". "I believe that everything starts with a plan. We have to plan out who are important to the school and who are not. Only from there we can know who to focus on".

Stakeholders are defined as groups or persons who are affected by and have the ability to influence the activities of an organisation [7]. More specifically, each stakeholder has a unique stake in the firm, which is a shared interest or undertaking [8]. As a result, organising these groups or individuals based on their importance and distinct stakes in the organisation is one of the first and most significant tasks in stakeholder management. As a result, Clarkson proposed categorising stakeholders into primary and secondary groups [2] in 1995. Primary Stakeholders: Individuals or groups involved in financial transactions who are essential to the organization's survival. Secondary Stakeholders: Organizations or persons who are not involved in financial transactions but have a moral or ethical stake in the activities of the organisation.

"Here at our Higher institution, we receive lots of enquires on a daily basis and it's impossible to personalise every reply. So, we organise them into hot-leads and cold-leads".

Clarkson's thesis of primary and secondary stakeholders is clearly reflected in the aforementioned response. It's impossible to devote attention to all stakeholders in this situation; instead, focus on those with the highest stakes. Students who inquire about hot leads are classed as "Primary Stakeholders," while students who inquire about cool leads are labelled as "Secondary Stakeholders." Nonetheless, this inclusion implies that interacting with all stakeholders is good, but the type of that communication should vary depending on the stakeholders' level of interest and stake. After all, secondary stakeholders, as well as primary stakeholders, have the power to influence public opinion (business reputation) in favour or against the company. Cold-lead students, for example, could tell their acquaintances about their unpleasant experience with Higher institution, hurting public opinion and, eventually, Higher institution's corporate brand.

\subsection{Stakeholder Communication}

"For naughty students, we simply cannot just communicate to the parents once. We have to constantly update them to see the progressive change in-school and out-school. Same goes for kiasu parents and students". "In the kindergarten industry, it's the first form of education for parents...... Parents act as advocates to their friends/family to join us as well. Its important to personally keep in touch with all of them".

Based on the replies above, it's evident that simply communicating with stakeholders isn't enough; it's necessary to maintain this constant kind of communication in order to engage with them. Based on Grunig and Hunt's communications theory [5], they can be categorised as follows. Engagement is defined as a two-way symmetrical communication paradigm that is relatively important for all organisations because it can:

- Promote better decision-making from further understanding 
- Strengthen corporate reputation from goodwill

- Build long-term relationships with stakeholders

- Is a continuous process and links to long-term business goals

"You see, what's the point of just having a marketing department promoting through social media and campaigns....... We most importantly need a recruitment team to engage with them in today's networked world".

\subsection{Integrating Stakeholder Management and Communication to become Stakeholder}

\section{Engagement}

Henceforth, the Power Interest Matrix is a matrix used to categorise stakeholders and promote effective management and engagement, providing the highest value to all stakeholder based on their unique stakes [6] .

"Usually, Kindergartens like to organise annual concerts with the children and invite their parents. This way, we keep in contact with them and engage with them by letting them see and experience their learning themselves". "With technology ever-growing, I think a great way parents can constantly monitor their children and engage with them is by developing a programme that allows parents to view their children's academic standing in real-time".

\begin{tabular}{|c|c|c|}
\hline$\uparrow$ & $\begin{array}{l}\text { Latent } \\
\begin{array}{l}\text { - } \quad \text { Existing Parents with first child enrolled } \\
\text { in kindergarten }\end{array}\end{array}$ & $\begin{array}{l}\text { Promoter } \\
\text { - Existing Parents with all children } \\
\quad \text { enrolled in kindergarten }\end{array}$ \\
\hline 3. & $\begin{array}{l}\text { Monitor } \\
\begin{array}{l}\text { - Parents who have decided not in enrol } \\
\text { in the kindergarten }\end{array}\end{array}$ & $\begin{array}{l}\text { Keep Informed } \\
\text { - Parents who are yet to decide where to } \\
\text { enrol children }\end{array}$ \\
\hline
\end{tabular}

Figure 1. Power Interest Matrix for parents looking to enrol children in kindergarten

Based on the Power Interest Matrix above, it's evident that kindergartens should focus on existing parents of all children enrolled in the kindergarten, as they may become champions for the kindergarten (Fig. 1). Promoting to their family and friends, as well as establishing a link to long-term client lifetime value (CLV). For example, incorporating their parents in annual performances at the kindergarten to include them in the child's learning and development process. If engaged with, Latent parents may become Promoter parents, while Keep Informed parents who have yet to enrol may become Latent parents. Monitor parents should, however, be involved if the opportunity arises, since they may tell their friends about their experience with the kindergarten, altering public opinion and, eventually, company reputation in contrast to other kindergartens.

\section{Corporate Reputation}

"Without proper stakeholder management, how can you expect your stakeholders to be happy with your organisation? We must continue engaging with them to promote a good corporate 
image". "Our school's image is dependent on students, parents and staff action. Stakeholders build up, create and determine corporate reputation".

Stakeholders develop a business reputation in general, and a strong reputation leads to a larger number of stakeholders supporting the organisation [9]. For example, we joined the organisation as students or workers because of the good reputation of the Higher institution. As a result, maintaining, growing, and protecting the corporate reputation with stakeholders requires projecting a favourable image or identity. This built-up business reputation therefore serves as an intangible asset, giving the company a "first choice" status among students, employees, and even investors [1].

\subsection{Image and Identity}

"Corporate Reputation stems from stakeholder engagement..... but there are so many ways to engage with stakeholders. We can see, speak, hear, and experience. Its important to engage with all the 5 senses of stakeholders". "For me, I think its easy to engage with an organisation that feels familiar..... For example, the police logo doesn't make me feel comfortable, and the $L V$ or GUCCI logo reminds me of money".

Corporate reputation is influenced by identity, image, and representation, which are all five senses in humans [10-11]. Corporate identity can refer to symbolism, such as logos (how we view and associate the Red Cross to hospitals), communication (how employees communicate across both traditional and media communication means), and behaviour (how employees leave an impression on stakeholders).

In my own experience, I recall not deciding to attend a particular university only because of the manner in which its employees conducted themselves. I perceived a lack of responsibility on the part of the employees, and as a result, their company reputation suffered. I didn't want to learn from a place that appeared to be unprofessional. Organizations present an image of themselves to their stakeholders through these traits, with corporate image being the image of an organisation (University) in the eyes of stakeholders (Future Students). More specifically, the term "identity" refers to the organization's strategic communication with external stakeholders as well as patterns of meaning-making and identification derived from symbolism, communication, and behaviour.

\subsection{Reputation and trust}

"Stakeholders build up, create and determine corporate reputation.... You simply cannot buy reputation off the 'pasar malam'”. "Everybody is going to say the same thing but, reputation is trust. Trust is reputation. For example, I trust that my education in Higher institution will be good because of their reputation". "We are the top $1 \%$ of Universities in the world. This is our reputation at Higher institution, and I always promote this to students and parents. It simply illustrates trust in our education programme...... Your son will be equipped for the global working world"

According to the answers above, a good reputation is more than just a gleaming medal; it's also a competitive advantage over competitors [3]. In times of crisis, for example, a history of excellent reputation can operate as a shield to protect market position and current stakeholder 
connections. However, this does not indicate that CSR automatically leads to improved corporate reputation. The continuous, transparent, honest, distinctive, and visible values that an organisation communicates to its stakeholders [4] are the fundamental driver of Corporate Reputation. So, what does this imply for businesses? How can they effectively boost corporate reputation by showcasing these values?

a. Trust must be earned through actions not fancy posts on social media. Organisations must do the right thing, and once completed then only showcase it clients and stakeholders. For instance, Higher institution must work hard to achieve a top $1 \%$ ranking in the world before able to showcase it to clients and stakeholders to build that trust that their education programme is truly value for money.

b. Think of the stakeholder's position, engage, and involve them inside continuous process of growth to build better experiences and relationships with the organisation.

c. Not everything comes with a price, provide stakeholders with education on your area of expertise and listen to their feedback. In this instance, free webinars can be held by Higher institution to help both primary and secondary stakeholders and listen to internal and external point of views and guide decision making.

But how does this relate to a company's image? Regardless of your position in the Power Interest Matrix, this is the "initial impression" you're delivering to stakeholders. You're demonstrating that your business practises are open and honest. This conveys an honest and real image of the brand, especially in times of crisis, because you've gone outside your mandated area of operations to deliver value to your organization's stakeholders. Finally, build the company as a trustworthy and leadership-worthy expert in the field. For example, in the future, if a parent gives another parent negative comments on a higher education school. As an advocate for the brand, the parent could refer back to their corporate reputation to refute the unfavourable criticism. Overall, corporate reputation is defined not only by talk and actions, but also by the organization's engagement in the actions of its stakeholders, which creates value and trust, as well as a two-way symmetrical communication for greater decision making that benefits not only the organisation, but also the stakeholders.

\section{Conclusions}

It was fascinating to observe how, even at different levels of the education business, different and comparable approaches for engaging with stakeholders to build excellent corporate reputation could be found. For example, hosting an annual concert at the kindergarten level is a fantastic method to involve parents as main stakeholders by including them in the educational process. In higher education, however, this would be absurd because students are already adults capable of making their own judgments. The interviewees were involved in the writing of this piece. It was critical for me to figure out the best way to acquire interviewees in order to establish and affirm trust in this essay for you, the readers. The interview was conducted via Google Forms because it was the most convenient way for me to engage with the interviewees as my stakeholders. Corporate reputation is defined not only by talk and actions, but also by the organization's engagement in the actions of its stakeholders, which creates value and trust, as well as a two-way symmetrical communication for greater decision making that benefits not only the organisation, but also the stakeholders. 


\section{Competing Interest}

No conflict of interest is declared

\section{References}

[1] Burke, P.F.; Dowling, G.; Wei, E. (2018). The Relative Impact of Corporate Reputation on Consumer Choice: Beyond a Halo Effect. Journal of Marketing Management, 34, 1227-1257. https://doi.org/10.1080/0267257X.2018.1546765.v

[2] Clarkson, M.B.E. (1995). The Management of Stakeholder Relationships in Totalitarian and Democratic Societies. Proceedings of the International Association for Business and Society, 6, 427-438. https://doi.org/https://doi.org/10.5840/iabsproc1995639.

[3] Flatt, S.J.; Kowalczyk, S.J. (2008). Creating Competitive Advantage through Intangible Assets: The Direct and Indirect Effects of Corporate Culture and Reputation. Journal of Competitiveness Studies, 16, 13.

[4] Fombrun, C.J.; Van Riel, C. (2004). Fame \& Fortune: How Successful Companies Build Winning Reputations. FT press: New Jersey, USA.

[5] Grunig, J.E., Grunig, L.A. (1992). Models of Public Relations and Communication. In Excellence in Public Relations and Communication Management; Grunig, J.E.; Lawrence Erbalum Associate: New Jersey, USA; pp. 285-325.

[6] Guðlaugsson, B.; Fazeli, R.; Gunnarsdóttir, I.; Davidsdottir, B.; Stefansson, G. (2020). Classification of Stakeholders of Sustainable Energy Development in Iceland: Utilizing a PowerInterest Matrix and Fuzzy Logic Theory. Energy for Sustainable Development, 57, 168-88. https://doi.org/10.1016/j.esd.2020.06.006.

[7] Jonker, J.; Foster, D. (2002). Stakeholder Excellence? Framing the Evolution and Complexity of a Stakeholder Perspective of the Firm. Corporate Social Responsibility and Environmental Management, 9, 187-195. https://doi.org/10.1002/csr.23.

[8] Mahanty, S.; Russell, D. (2002). High Stakes: Lessons from Stakeholder Groups in the Biodiversity Conservation Network. Society \& Natural Resources, 15, 179-188. https://doi.org/10.1080/089419202753403346.

[9] Mahon, J.F.; Wartick, S.L. (2003). Dealing with Stakeholders: How Reputation, Credibility and Framing Influence the Game. Corporate Reputation Review, 6, 19-35. https://doi.org/10.1057/palgrave.crr.1540187.

[10] Pruzan, P. (2001). Corporate Reputation: Image and Identity. Corporate Reputation Review, 4, 50-64. https://doi.org/10.1057/palgrave.crr.1540132.

[11] Mohamad, B.; Adamu, A.A. (2018). Exploring The Relationship Between Corporate Culture, Ict Diffusion Innovation, Leadership and Organizational Performance.

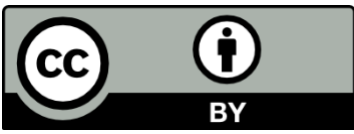

(C) 2021 by the authors. This article is an open access article distributed under the terms and conditions of the Creative Commons Attribution (CC BY) license (http://creativecommons.org/licenses/by/4.0/). 